\title{
Avaliação da política de gestão aplicada à extensão universitária na Universidade Federal Rural do Rio de Janeiro
}

\author{
Evaluation of the management policy applied to university extension at the Federal \\ Rural University of Rio de Janeiro
}

Camila Eller Gomes ${ }^{1}$

\section{RESUMO}

Levando em consideração o papel que a política pública de extensão universitária representa para produção de mudanças socioculturais relevantes à vida humana civilizada e para construção de uma sociedade mais equitativa, é que se propõe o presente estudo. Um estudo que consiste na avaliação da política de gestão empregada pela Universidade Federal Rural do Rio de Janeiro às ações de extensão universitária por ela implementadas. Para tal, foi utilizada a metodologia de estudo de caso, numa abordagem qualitativa, que a partir da análise de um conjunto de indicadores teve como objetivo compreender se a política de extensão universitária avaliada apresenta procedimentos de gestão sistematizados capazes de institucionalizar e estimular sua plena implementação, de forma a contribuir para o fortalecimento da instituição e para melhoria da qualidade na formação de futuros profissionais. Ao final do estudo chega-se a um diagnóstico da situação observada que permitiu, a partir da identificação de pontos fortes e fracos, oportunidades e ameaças institucionais, elencar um conjunto de recomendações com vistas a reforçar as potencialidades e minimizar as fragilidades observadas.

Palavras-chaves: Extensão universitária. Políticas públicas. Avaliação.

\begin{abstract}
Taking into account the role that the public policy of university extension represents for the production of sociocultural changes relevant to civilized human life and for the construction of a more equitable society, this study is proposed. A study that consists of evaluating the management policy employed by the Federal Rural University of Rio de Janeiro to the university extension actions implemented by it. To this end, the case study methodology was used, in a qualitative approach, which, based on the analysis of a set of indicators, aimed to understand whether the evaluated university extension policy presents systematized management procedures capable of institutionalizing and encouraging its full implementation, in order to contribute to the strengthening of the institution and to improve the quality of training for future professionals. At the end of the study, a diagnosis of the observed situation was reached, which allowed, based on the identification of institutional strengths and weaknesses, opportunities and threats, to list a set of recommendations aimed at strengthening the potential and minimizing the observed weaknesses.
\end{abstract}

Keywords: University extension. Public policies. Evaluation.

\footnotetext{
${ }^{1}$ Mestra em Engenharia de Produção pela Universidade Federal do Rio de Janeiro, Brasil; técnica administrativa na Pró-reitoria de Extensão da Universidade Federal Rural do Rio de Janeiro, Brasil (camilaeller@ufrrj.br).
} 


\title{
INTRODUÇÃO
}

Os princípios norteadores das atividades de extensão estão presentes e fundemse à própria história de formação das universidades brasileiras. Ao longo da trajetória de criação e consolidação do Ensino Superior no Brasil foi gerada uma série de reflexões acerca das ações desenvolvidas pela extensão, dentre as quais podemos dar destaque àquelas que se preocupam em concebê-las como práticas que ultrapassam o viés puramente assistencialista e como processo que articula o ensino e a pesquisa, indo além da prática extensionista tradicionalmente entendida como a disseminação de conhecimentos, a prestação de serviços ou a difusão cultural.

Reforçando a compreensão de sua importância como política de Estado e como ação articuladora entre o pensar/fazer universitários e a sociedade, é que, no ano de 1987, constitui-se o Fórum de Pró-Reitores de Extensão das Universidades Públicas (FORPROEX), e é em 1988, durante o I Encontro Nacional de Pró-Reitores de Extensão que assim definiu o conceito de Extensão Universitária:

\begin{abstract}
A Extensão Universitária é o processo educativo, cultural e científico que articula o Ensino e a Pesquisa de forma indissociável e viabiliza a relação transformadora entre universidade e sociedade. [Num] fluxo, que estabelece a troca de saberes sistematizados, acadêmico e popular, [que] terá como consequência: a produção do conhecimento resultante do confronto com a realidade brasileira e regional; a democratização do conhecimento acadêmico e a participação efetiva da comunidade na atuação da Universidade. (FORPROEX, 1987).
\end{abstract}

A indissociabilidade entre ensino, pesquisa e extensão passa a ser um princípio legal previsto no artigo 207 da Constituição Brasileira (BRASIL, 1988). Caracterizando-se, a partir daí, como uma função obrigatória da universidade brasileira.

Desde então, é grande o debate e os desafios, sejam de ordem administrativa, acadêmica ou financeira relacionados à institucionalização das atividades de extensão de forma a garantir sua sistematização como política pública de construção de uma universidade "voltada para os problemas sociais com o objetivo de encontrar soluções através da pesquisa básica e aplicada, visando realimentar o processo ensinoaprendizagem como um todo e intervindo na realidade concreta" (FORPROEX, 2013).

Daí depreende-se a relevância deste estudo avaliativo que analisará aspectos relevantes da implementação da política de extensão universitária a fim de propor ações 
que potencializem seu desenvolvimento no âmbito de uma instituição pública de Ensino Superior.

O objetivo geral deste trabalho é compreender se a Gestão da Política de Extensão Universitária adotada pela Universidade Federal Rural do Rio de Janeiro (UFRRJ) vem apresentando processos sistematizados capazes de institucionalizar e estimular tal política. Contribuem para o alcance do objetivo geral os seguintes objetivos específicos: I) Selecionar os indicadores da dimensão política de gestão a serem avaliados; II) Demonstrar a importância estratégica da extensão universitária para a instituição; III) Explicar o nível de sistematização da extensão na estrutura universitária e sua estrutura de gestão; e IV) Esquematizar pontos fortes e fracos, oportunidades e ameaças a partir da elaboração de uma matriz SWOT.

Parte-se da hipótese de que o método de Gestão da Política Pública de Extensão adotada pela UFRRJ possui processos sistematizados que contribuem para incorporação da função extensionista em sua estrutura.

A partir da metodologia de estudo de caso, associada à técnica de pesquisa documental, o artigo desenvolve a análise do conjunto de indicadores que compõem a dimensão "Política de Gestão", tal como definido pelo Programa de Avaliação do Forproex (2017). Para tal, considerou dados relativos às ações de extensão oficialmente registradas junto à Pró-Reitoria de Extensão (Proext) da UFRRJ, que concentra as atividades desenvolvidas nos campi Seropédica, Nova Iguaçu e Três Rios, no período de cinco anos, que vai de 2015 a 2019.

A partir dessa introdução, este artigo está estruturado em seis seções: referencial teórico, que discorre sobre o conceito de políticas públicas, seus métodos de avaliação e sobre a avaliação da extensão universitária; método de produção técnica; o contexto do projeto; apresentação e análise dos resultados; e considerações finais.

\section{REFERENCIAL TEÓRICO}

\section{Políticas Públicas}

A bibliografia não aponta uma definição pacífica para o conceito de política pública e isto se dá especialmente pela existência dos diversos posicionamentos frente a questões ligadas à natureza do ator promotor, à intencionalidade e ao nível de operacionalização de uma política pública (PP). 
No contexto deste trabalho há um alinhamento ao entendimento apresentado por Secchi (2010), no qual se preconiza como essência conceitual de política pública a orientação tomada com objetivo de solucionar um problema público, ou seja, um problema entendido como coletivamente relevante.

Para além desse entendimento inicial, e complementando a discussão sobre o tema, Frey (2000) observa que a política pública é composta por três dimensões que precisam ser consideradas, seja para sua compreensão ou para estruturação de um processo de pesquisa na análise de PP ou do policy analisys, são elas: (i) policy: os conteúdos concretos da política, sua configuração, seus problemas técnicos, ou seja, o processo de construção e atuação das decisões políticas; (ii) politics: os processos políticos que modelam a determinação de objetivos, conteúdos e decisões; e o (iii) polity: as instituições políticas que se referem à ordem e à estrutura institucional do sistema político-administrativo.

Muito embora essas três dimensões apareçam de forma entrelaçada e se influenciem mutuamente, considerar esses aspectos peculiares da política é útil para observação do processo político envolvido, para escolha de seu nível de análise e para percepção dos graus de dependência/independência das variáveis que as compõem.

No que se refere aos modelos explicativos empregados para análise de políticas públicas, a literatura nos oferece uma gama de abordagens dentre as quais podemos destacar: o ciclo de política pública (policy cycle approach); o modelo lata de lixo (garbage can), de Cohen, March e Olsen; o modelo de coalizão de defesa (advocacy coalition), de Sabatier e Jenkins-Smith; o modelo de arenas sociais e o modelo do equilíbrio interrompido (punctuated equilibium), de Baumgartner e Jones (SOUZA, 2006).

No âmbito deste artigo, daremos destaque ao modelo do policy cycle approach (abordagem do ciclo de políticas), que subdivide "o agir público em fases parciais do processo político-administrativo de resoluções de problemas” públicos (FREY, 2000), enxergando "a política pública como um ciclo deliberativo, formado por vários estágios e constituindo um processo dinâmico e de aprendizado" (SOUZA, 2006).

Frey (2000) destaca que as propostas encontradas na bibliografia para esquematizar as divisões do ciclo político se diferenciam entre si de forma gradual. Segundo o autor, são comuns a todas as propostas as fases de: (I) formulação, (II) implementação; e (III) controle dos impactos das políticas/avaliação. Subdivisões mais refinadas têm sido construídas com o objetivo de contribuir para o processo analítico 
das PP. Secchi (2010), por exemplo, apresenta uma configuração que considera sete fases principais no ciclo de política: (I) identificação do problema, (II) entrada na agenda, (III) formulação de alternativas, (IV) tomada de decisão, (V) implementação, (VI) avaliação e (VII) extinção da política pública.

\section{Avaliação de Políticas Públicas}

Segundo Souza (2006), a política pública envolve processos que são subsequentes às fases de decisão e proposição, abrange também a implementação, a execução e a avaliação. A avaliação da PP pode ser definida como o "processo de julgamentos deliberados sobre a validade de propostas para a ação pública, bem como sobre o sucesso ou a falha de projetos que foram colocados em prática" (ANDERSON, 1979, p. 71 apud SECCHI, 2010).

Fraco e Cohen (apud VIANA, 1996) acrescentam que os estudos para avaliação de políticas podem se diferenciar em função de uma série de características, são elas: o momento em que são realizados, o objeto de estudo considerado, os objetivos, as técnicas empregadas e a relação que estabelecem com a política.

Quando consideramos o momento em que ocorre, as avaliações podem ser classificadas em: (I) avaliação ex ante, aquela que ocorre antes da implementação da política, (II) avaliação ex post, que se dá após a implementação da política, ou (III) avaliação in intinere, (formativa ou monitoramento) realizada durante o processo de implementação (TREVISAN; VAN BELLEN, 2008).

As avaliações ex post podem ser de dois tipos: de processo ou de impacto. Nas avaliações de processo o objeto de estudo é a aferição e adequação entre meios e fins, com o objetivo de permitir a correção do modelo de implementação, reorientando-o em função dos objetivos propostos. Nas avaliações de impacto, o objeto é a medição de resultados dos efeitos das políticas implementadas, com o objetivo de identificar quais foram as contribuições dos diferentes componentes da política para realização de seus objetivos (VIANA, 1996).

A correlação entre o tipo de avaliação pretendida e as fases das PP analisadas requer a definição de critérios, indicadores e padrões que permitam julgar qualitativamente seu funcionamento (SECCHI, 2010). Os critérios servem como base para escolhas ou julgamentos, pois se fundamentam em entendimentos de valor da realidade, tais como: economicidade, eficiência econômica, eficiência administrativa, 
eficácia, equidade, efetividade e são operacionalizados por meio de indicadores. Estes, por sua vez, são medidas usadas para permitir a operacionalização de um conceito abstrato ou de uma demanda de interesse programático. Apontam, indicam, medem em termos operacionais, os inputs (entradas do sistema), os outputs (saídas do sistema) e os outcomes (resultados) de interesse, que estão relacionados às políticas públicas em análise (JANNUZZI, 2005; SECCHI, 2010).

Tendo em mente os critérios e indicadores a serem utilizados, o passo seguinte é o de fazer as comparações com os padrões de referência, ou parâmetros, a fim de julgar o desempenho da política analisada. Tais padrões de referência podem ser classificados em: (I) absolutos - metas estabelecidas anteriormente à implementação da política pública; (II) históricos - comparação dos resultados ao longo do tempo; (III) normativos - comparações com programas similares ou semelhantes; (IV) teóricos estabelecidos na própria elaboração do programa, sob a hipótese da obtenção dos resultados planejados; e (V) negociados ou de compromisso - fixados a partir do acordo entre as partes envolvidas na gestão do programa (COSTA; CASTANHAR, 2003).

São inegáveis as potencialidades apresentadas pelos estudos de avaliação em políticas públicas. No entanto, Trevisan e Van Bellen (2008) destacam que a avaliação de PP ainda é pouco utilizada. Secchi (2010) pontua uma série de questões que contribuíram para essa realidade: a dificuldade para realização de avaliações completas e significativas; a multicausalidade envolvida, que torna difícil separar efeitos sociais decorrentes da política pública e aqueles decorrentes de outras causas; a resistência apresentada por quem é objeto da avaliação; a forma de apresentação dos resultados; o tempo de maturação de uma política pública até que ela apresente efeitos; os interesses em jogo por parte de usuários, partidos políticos, patrocinadores das políticas, agências responsáveis por sua execução, atores encarregados pela avaliação, entre outros. Questões que também podem influenciar o uso das informações e os resultados das avaliações.

\section{Avaliação da extensão universitária}

Após uma série de debates, e como consequência de uma das metas traçadas no Plano Nacional de Extensão, em especial aquela que versa sobre a "elaboração de uma proposta de Programa Nacional de Avaliação da Extensão Universitária das universidades brasileiras" (FORPROEX, 1999), é que, no ano de 2001, o Forproex 
lançou a proposta de avaliação da ação extensionista das Instituições de Ensino Superior Públicas (IESPs). A Avaliação Nacional da Extensão Universitária emergiu como resultado da necessidade de um processo institucional de valorização e reconhecimento da extensão como parte do fazer acadêmico e como um dos parâmetros de avaliação da universidade.

Em seu primeiro encontro, o Forproex ressaltou que a institucionalização da política de extensão passa pela adoção de três grupos de medidas e procedimentos necessários ao direcionamento das atividades acadêmicas às questões de relevância social, são eles: (I) medidas e procedimentos de ordem metodológica, (II) medidas referentes à estrutura universitária e (III) medidas para valorização da extensão regional e nacional (FORPROEX, 1987). Em consonância com essas diretrizes, a proposta de avaliação da extensão foi concebida de forma a considerar três níveis inter-relacionados: o compromisso institucional para a estruturação e efetivação das atividades de extensão; o impacto das atividades de extensão junto aos segmentos sociais que são alvos ou parceiros dessas atividades; e os processos, métodos e instrumentos de avaliação das atividades de extensão (FORPROEX, 2001).

A definição desses três níveis pautou a identificação das dimensões do sistema de avaliação ora concebido e de seus respectivos indicadores. O Programa de Avaliação do Forproex abrange ao todo cinco dimensões, descritas no quadro 1, e um total de 52 indicadores.

Quadro 1 - Dimensões de investigação da extensão universitária

\begin{tabular}{|l|l|}
\hline \multicolumn{1}{|c|}{ Dimensão } & \multicolumn{1}{|c|}{ Descrição } \\
\hline I - Política de Gestão & $\begin{array}{l}\text { Está contida nas finalidades, objetivos, fomento e } \\
\text { atribuições da extensão. Bem como seus instrumentos } \\
\text { de ação, denuncia se a universidade incorpora a } \\
\text { função extensionista. }\end{array}$ \\
\hline II - Infraestrutura & $\begin{array}{l}\text { Informa sobre as condições físicas e gerenciais, reais, } \\
\text { da realização da extensão e sobre as possibilidades de } \\
\text { se consolidarem as metas almejadas. }\end{array}$ \\
\hline III - Relação Universidade-Sociedade & $\begin{array}{l}\text { Revela de que modo as atividades de extensão estão } \\
\text { presentes na sociedade, quais seus pressupostos e } \\
\text { finalidades e como interagem com a sociedade no } \\
\text { sentido de transformações recíprocas. }\end{array}$ \\
\hline
\end{tabular}




\begin{tabular}{|l|l|}
\hline IV - Plano Acadêmico & $\begin{array}{l}\text { Analisa as possibilidades de incorporação da extensão } \\
\text { na vida acadêmica, valorizando as experiências } \\
\text { desenvolvidas pelo conjunto de participantes na ação } \\
\text { extensionista (professores, funcionários e alunos). }\end{array}$ \\
\hline V - Produção Acadêmica & $\begin{array}{l}\text { Trata da captação dos produtos resultantes da ação da } \\
\text { extensão, que elabora e dissemina conhecimentos e } \\
\text { que, no âmbito universitário, tem o seu valor } \\
\text { reconhecido. }\end{array}$ \\
\hline
\end{tabular}

Fonte: FORPROEX (2001).

\section{MÉTODO DA PRODUÇÃO TÉCNICA}

De natureza aplicada, o procedimento da pesquisa foi desenvolvido pela técnica da pesquisa documental, caracterizada pela pesquisa "de materiais que não receberam ainda um tratamento analítico, ou que ainda podem ser reelaborados de acordo com os objetos da pesquisa" (GIL, 2008, p. 45) associada ao estudo de caso, dado que ela se adequa à proposta de um trabalho de caráter empírico que investiga um dado fenômeno dentro do contexto real contemporâneo por meio da análise aprofundada de um objeto de análise - caso (CAUCHICK-MIGUEL et al., 2012).

De acordo com sua finalidade a pesquisa classifica-se como descritiva, pois tem como principal objetivo a "descrição das características de determinada população ou fenômeno" (GIL, 2008).

Para o levantamento dos dados, foram consultados registros oficiais contidos nos arquivos físicos e digitais da Proext/UFRRJ, e documentos normativos da instituição, tais como: deliberações, resoluções e afins, disponibilizados em seu site oficial, dos quais foi extraído um conjunto de dados primários e secundários que subsidiaram a análise diagnóstica dos indicadores. Os dados foram tabulados com o uso de planilhas eletrônicas.

A unidade de análise deste artigo foi a política de extensão universitária implementada pela instituição. Em relação ao tratamento dos dados, a pesquisa é considerada qualitativa, pois não envolveu análises estatísticas.

No que se refere à abordagem temporal, o presente estudo se caracteriza como pesquisa de corte longitudinal, uma vez que os dados coletados tratam da evolução do fenômeno estudado ao longo do tempo, sendo ainda do tipo retrospectivo, pois baseia-se 
em dados de períodos pretéritos (ALENCAR, 2012; BIROCHI, 2015, p. 66). Optou-se pelo uso de padrões de referência históricos para julgar o desempenho da política analisada. Cabe destacar que o intervalo considerado de 5 anos (2015 a 2019) situa-se num período de tempo compreendido entre o exercício parcial de duas diferentes gestões administrativas. A escolha do período se deveu principalmente para garantir a disponibilidade dos dados necessários à elaboração da análise, já que foi detectado que haveria grande dificuldade em recuperar dados de períodos anteriores.

O padrão de formalização da política de extensão na estrutura organizacional da UFRRJ foi delineado com base na análise dos indicadores que compõem a dimensão "Política de Gestão", tal como definida pelo Programa de Avaliação do Forproex, conforme apresentado no quadro abaixo.

Quadro 2 - Indicadores de política de gestão

\begin{tabular}{|c|c|}
\hline $\begin{array}{l}\text { Dimensão de } \\
\text { avaliação }\end{array}$ & Indicadores \\
\hline \multirow{13}{*}{$\begin{array}{l}\text { Política de Gestão } \\
\qquad(\mathrm{PG})\end{array}$} & PG1: Importância estratégica da Extensão Universitária \\
\hline & PG2: Estrutura organizacional de suporte à Extensão Universitária \\
\hline & PG3: Institucionalização de programas e projetos de extensão \\
\hline & $\begin{array}{l}\text { PG4: Valorização da prática extensionista como critério de } \\
\text { promoção na carreira }\end{array}$ \\
\hline & $\begin{array}{l}\text { PG5: Formação em gestão da extensão para servidores dos } \\
\text { órgãos/setores responsáveis pela extensão }\end{array}$ \\
\hline & PG6: Participação dos servidores da extensão em eventos da área \\
\hline & $\begin{array}{l}\text { PG7: Capacitação em extensão promovida ou apoiada pela Pró- } \\
\text { reitoria (ou equivalente) aberta à comunidade acadêmica }\end{array}$ \\
\hline & PG8: Garantia da qualidade na extensão \\
\hline & $\begin{array}{l}\text { PG9: Taxa de aprovação de propostas de extensão em editais } \\
\text { externos }\end{array}$ \\
\hline & PG10: Taxa de conclusão de ações de extensão \\
\hline & PG11: Recursos do orçamento anual público voltado para extensão \\
\hline & PG12: Recursos para extensão captados via edital público externo \\
\hline & $\begin{array}{l}\text { PG13: Recursos para extensão captados via prestação de serviços } \\
\text { acadêmicos especializados }\end{array}$ \\
\hline
\end{tabular}

Fonte: Forproex (2017). 
No que se refere aos indicadores de natureza quantitativa, a população da pesquisa é representada pelas ações de extensão desenvolvidas no âmbito da UFRRJ e que tenham sido oficialmente registradas junto à Proext. Também fazem parte da população, de acordo com os indicadores ora estudados, o conjunto de servidores lotados nessa Pró-reitoria.

\section{Contexto do projeto}

Como política pública de Estado, a Política de Extensão encontra limites, de natureza estrutural ou conjuntural, que afetam diretamente seu pleno desenvolvimento. Sendo assim, a necessidade de enfrentá-los se põe como tarefa imprescindível para a garantia de sua existência enquanto atividade produtora de conhecimento capaz de estimular o desenvolvimento ético, humano e sustentável. Esse enfrentamento passa pelo atendimento, no âmbito das Instituições de Ensino Superior (IES), às diretrizes de Extensão na Educação Superior Brasileira recentemente estabelecidas pelo Conselho Nacional de Educação (CNE), que define "princípios, fundamentos e procedimentos a serem observados no planejamento, nas políticas, na gestão e na avaliação das instituições de educação superior de todos os sistemas de ensino do país" (BRASIL, 2018).

Para dar sequência ao ciclo virtuoso ao qual as ações de extensão são capazes de conduzir, é indispensável a implementação de um processo de avaliação que contribua para o aperfeiçoamento da prática extensionista.

Tendo em mente a relevância que as ações e a extensão têm para "produção de mudanças socioculturais relevantes à vida humana civilizada, na direção da construção de uma sociedade mais equitativa" (GATTI, 2004), apresentando-se como elemento indissociável na constituição das universidades brasileiras, trazemos a proposta deste artigo que consiste na avaliação da Política de Gestão empregada pela UFRRJ.

A UFRRJ é multicampi, cuja sede encontra-se localizada na cidade de Seropédica, região da Baixada Fluminense. Atualmente oferece 56 cursos de graduação, 2 cursos de graduação na modalidade a distância, 25 cursos de mestrado acadêmico, 8 cursos de mestrado profissional e 14 cursos de doutorado, abrigando aproximadamente 24 mil estudantes de graduação e 2 mil estudantes de pós-graduação (UFRRJ, 2019). 
Historicamente ligada aos cursos de agrárias, exatas e biológicas viu seu perfil sendo modificado à medida que, com a implementação do Programa de Apoio a Planos de Reestruturação e Expansão das Universidades Federais (Reuni), foram criados novos cursos nas áreas de Ciências Humanas e Sociais Aplicadas (UFRRJ, 2019). Para além de atender a política pública de ampliação do acesso ao Ensino Superior, essa opção, por expandir-se nessas áreas do conhecimento, procura responder às demandas sociais da Baixada Fluminense. Entendemos que a formação adequada de profissionais é em muito enriquecida com as experiências desenvolvidas no âmbito da Extensão Universitária.

A Universidade, em sua essência, tem um importante papel de responsabilidade social a cumprir, formando profissionais comprometidos com a sociedade, preservando culturas, zelando pelos direitos humanos e compartilhando conhecimento. Para tanto é imprescindível que ela mantenha diálogo intenso, via ação de mão-dupla, com os diferentes setores da sociedade. Por sua vez, a qualificação e fortalecimento de todas as experiências e saberes ligados ao fazer extensionista necessitam de sistematização, de forma a contar com processos de planejamento, metodologia e avaliação.

Ao final do estudo, espera-se delinear de forma abrangente, mas nítida, como a Universidade incorpora a política de extensão à sua estrutura formal de funcionamento, destacando suas potencialidades e fragilidades.

\section{RESULTADOS OBTIDOS E ANÁLISE}

Nesta seção, apresentamos os dados relacionados a cada um dos indicadores examinados e sua respectiva análise. No anexo A, é possível encontrar um quadroresumo com a descrição dos indicadores avaliados.

Cabe registrar que, em virtude de características relacionadas à natureza do trabalho que subsidiou a construção deste artigo (tamanho, tempo, profundidade e amplitude) foram analisados somente 10 dos 13 indicadores previamente selecionados. O rol completo e a descrição pormenorizada dos indicadores podem ser consultados em sua integralidade na obra Indicadores Brasileiros de Extensão Universitária (FORPROEX, 2017). Na análise deste trabalho, foram excluídos os indicadores que envolviam dados vinculados ao orçamento financeiro universitário. A escolha se deu em função do grau de dificuldade associado à obtenção de tais dados. 


\section{Importância estratégica da extensão universitária}

A partir da análise do conjunto de documentos que regulam o funcionamento da UFRRJ e planejam seu desenvolvimento estratégico, a saber: o Estatuto Universitário, o Regimento Geral e os Planos de Desenvolvimento Institucional (PDI) dos períodos de 2013-2017 e 2018-2022, fícou evidenciado: a) a caracterização da extensão Universitária tanto no Estatuto (art. 38) como no Regimento Geral da UFRRJ; b) a presença do conceito e a especificação de objetivos estratégicos e metas institucionais para extensão nos PDI; c) a presença da extensão na explicitação da missão institucional.

É importante destacar que, em comparação ao PDI 2013-2017, o Plano que compreende o período 2018-2022 apresenta uma estrutura mais robusta, baseada nas diretrizes estabelecidas pelo Decreto n. 5.773 de 9 de maio de 2006 (atualmente revogado pelo Decreto n. 9,235 de 15 de dezembro de 2017). Essa evolução permitiu evidenciar, de forma mais pormenorizada, o Plano de Objetivos e Metas Institucionais para o período, no qual se encontra uma série de objetivos estratégicos para extensão.

\section{Estrutura organizacional de suporte à extensão universitária}

A organização da extensão também está presente na estrutura de gestão da UFRRJ que conta com um conjunto, conselhos ou colegiados superiores, responsáveis pela normatização e estabelecimento da política institucional de extensão e pelo processo de aprovação, acompanhamento e avaliação, distribuição de recursos e bolsas, são eles:

- Conselho de Ensino, Pesquisa e Extensão - CEPE - estabelece diretrizes, coordena e supervisiona todas as atividades de ensino, pesquisa e extensão (UFRRJ, 2012, p. 9);

- Conselho de Ensino, Pesquisa e Extensão de Área - CEPEA - o órgão superior que estabelece a política acadêmica por área de conhecimento, deliberando sobre todos os assuntos relativos à atividades de Ensino, Pesquisa e Extensão da Área, nos limites das normas estabelecidas pelo CEPE (UFRRJ, 2012, p. 10);

- Conselho de Unidade - CONSUNI - propor políticas e ações de pesquisa e extensão para integrar e fortalecer competências da área de conhecimento (UFRRJ, 2012, p. 34); 
- Pró-Reitoria de Extensão - responsável pela gestão central, política de extensão, organização, registro e fomento das ações (UFRRJ, 2019, p. 1);

- Câmara de Extensão - tem como principal finalidade articular as ações de extensão em conformidade à Política de Extensão da UFRRJ, ao Regimento da Pró-Reitoria de Extensão e ao Plano Nacional de Extensão Universitária (UFRRJ, 2019, p. 1);

- Escola de Extensão - tem como objetivo principal estimular o oferecimento de cursos de extensão pela UFRRJ, ampliando, dessa forma, a transferência de conhecimentos disponíveis na Universidade para a Comunidade (UFRRJ, 2019, p. 1).

Nota-se a ausência de publicização de documento que apresente o Plano da Extensão, que divulgue o plano de atuação da Proext de forma mais precisa. Destaca-se que, em seu art. $9^{\circ}$, a deliberação CEPE $n^{\circ} 125$, de 6 de julho de 2006, faz menção ao "Plano Institucional de Extensão da UFRRJ", indicando os responsáveis por sua elaboração. De certa forma, as diretrizes macro desse plano estão contidas no PDI da Universidade, mas de forma bastante difusa. O estabelecimento de um plano institucional de extensão que aborde conceito, diretrizes, finalidades e funções da extensão universitária capaz de desdobrar a política de extensão numa série de ações distintas e coordenadas ao longo do tempo, sem dúvida traria um conjunto de benefícios que contribuiriam para o alcance das metas estabelecidas.

\section{Institucionalização de programas e projetos de extensão}

Os dados apresentados no gráfico 1 permitem destacar que a proporção entre alunos regularmente matriculados e programas/projetos institucionalizados apresentaram, nos últimos três anos, tendência de redução. Situação que sugere o aumento mais representativo do nível de institucionalização de programas e projetos de Extensão ao longo dos anos. Cabe-nos aqui enfatizar que, no âmbito deste artigo, o termo projetos e/ou programas institucionalizados refere-se àqueles projetos $\mathrm{e}$ programas que possuam registro formal junto à Proext da UFRRJ.

Destaca-se que essa crescente institucionalização indica ganhos em termos de aumento da capilaridade e alcance dessas ações dentro da universidade. Esse aumento no nível de institucionalização pode ser reflexo de dois movimentos não excludentes 
entre si e que foram alvo de ações da Proext: (i) o crescimento da oferta de programas e projetos de extensão e (ii) o crescimento da protocolização de tais ações.

Gráfico 1 - Institucionalização de programas e projetos de extensão

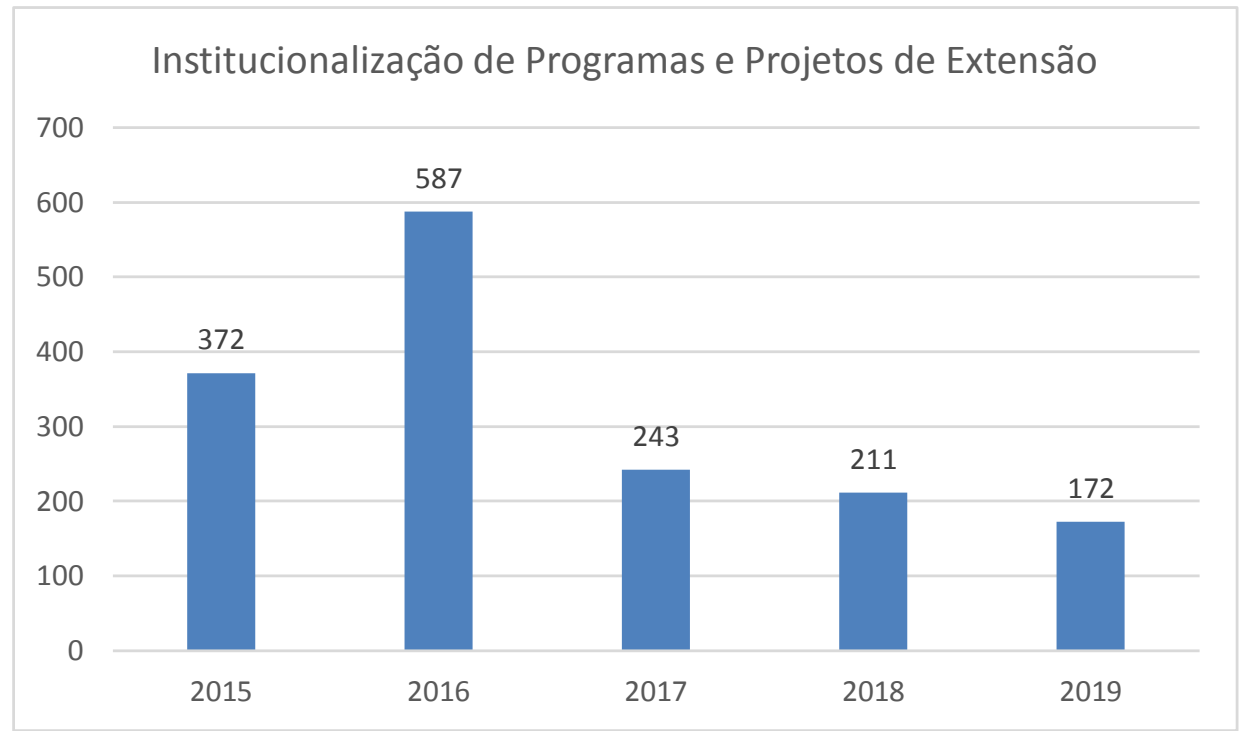

Fonte: A autora (2020).

\section{Valorização da prática extensionista como critério de promoção na carreira}

Muito embora o envolvimento em ações de extensão seja levado em conta nos procedimentos de progressão funcional da categoria docente, o que se constata é que ainda não existe a institucionalização de um "barema", com critérios padronizados de promoção funcional que promova a valorização da prática extensionista dentro da carreira docente. Atualmente essa avaliação aparece de forma heterogênea e difusa, com critérios diferenciados para cada departamento e contendo pesos diferentes entre si.

No caso dos servidores técnico-administrativos, embora os critérios de avaliação sejam homogêneos, não existe item específico que leve em conta o envolvimento em ações extensionistas. Recomenda-se que haja um esforço no sentido de implementar critérios homogêneos que considerem o fazer extensionista tão importante para promoção na carreira quanto os fazeres ligados ao ensino e à pesquisa. 


\section{Formação em gestão da extensão para servidores dos órgãos/setores responsáveis pela extensão}

A série de dados apresentada no gráfico 2, dada pela proporção entre o número de horas de treinamento por servidor lotado nos órgãos/setores responsáveis pela extensão, evidencia que existe grande deficiência na promoção de formação específica na área de gestão da extensão para tais servidores. De fato, não existe grande oferta externa de cursos voltados a essa temática, nem mesmo nos congressos e encontros da área, o que faz com que as atividades relacionadas a essa questão muitas vezes necessitem ser alvo de iniciativas internas à instituição.

No período analisado, o único ano em que houve aumento na proporção de servidores da extensão capacitados se deveu justamente a uma iniciativa de treinamento interno, relacionada aos primeiros passos de implementação de um sistema acadêmico informatizado para gestão das ações de extensão no âmbito da UFRRJ, o SIGAA Extensão. E mesmo assim sequer se atingiu a oferta de uma hora de treinamento por servidor.

No período analisado, o número absoluto de servidores lotados nos departamentos e setores da Proext ficou numa faixa que foi de 41 a 45 profissionais.

Gráfico 2 - Formação em Gestão da Extensão

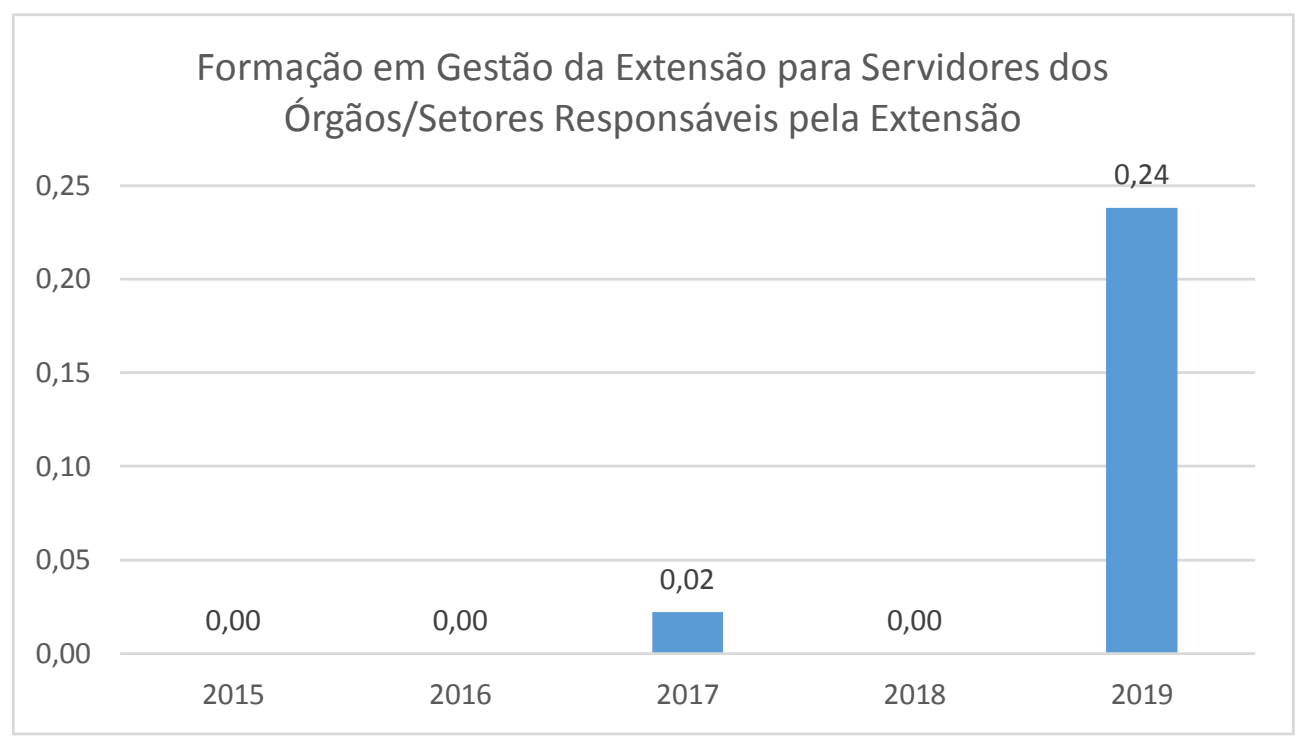

Fonte: A autora (2020). 


\section{Participação dos servidores da extensão em eventos da área}

O cálculo dado pela proporção entre o número de participações ativas em eventos de extensão pelo número total de servidores da extensão demonstra que o período analisado apresenta irregularidade na proporcionalidade de participação em eventos de extensão pelos servidores lotados na Proext, como observado no gráfico 3. Seria importante, mesmo com todas as restrições de natureza financeira que possam existir, investir na manutenção ou aumento dessa proporção ao longo dos anos.

Cabe ainda destacar que, quando se observam os números de forma menos agrupada, percebe-se a participação recorrente dos servidores de apenas alguns dos departamentos que compõem a Proext. Pensar numa estratégia que promova a participação mais representativa do corpo técnico da Proext em eventos da área seria muito importante para atualização e motivação desses profissionais. A participação em eventos dessa natureza tende a refletir na formação de redes de conhecimento entre servidores de área que favorecem a troca de saberes, um importante instrumento para o aperfeiçoamento da gestão.

Gráfico 3 - Participação dos servidores de extensão em eventos da área

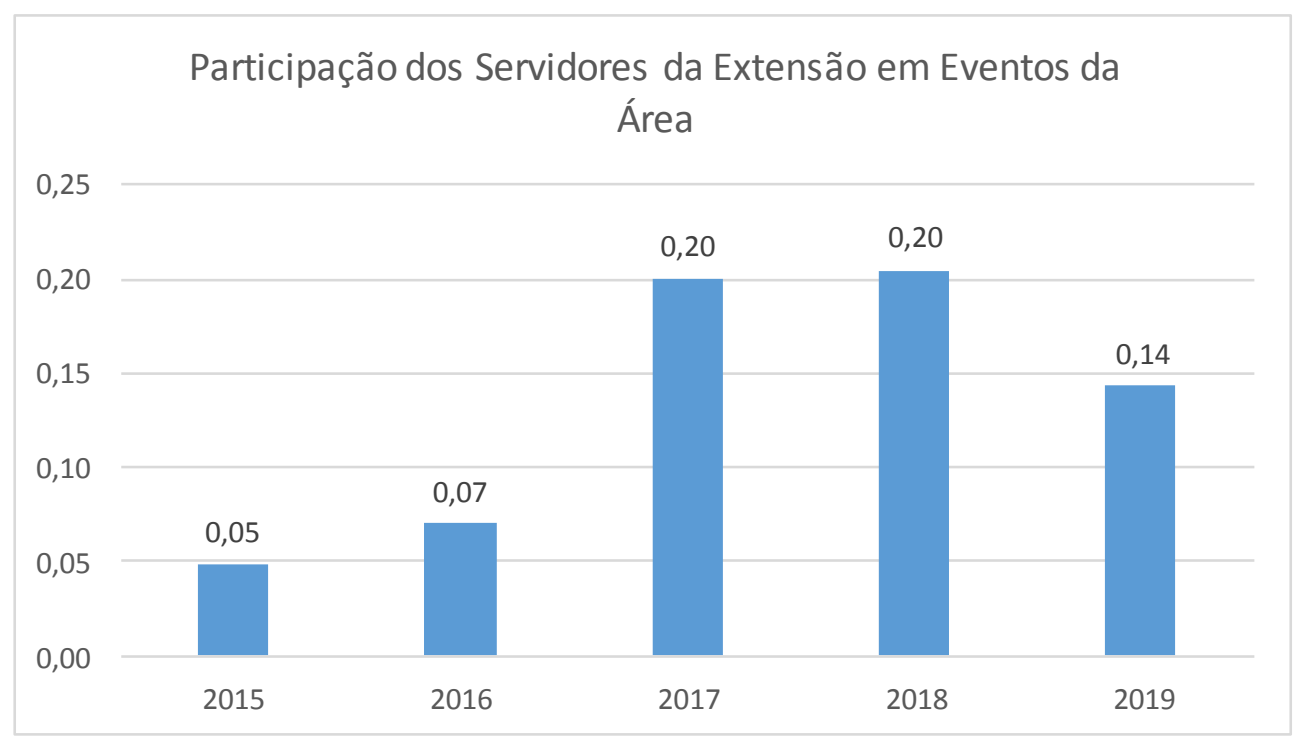

Fonte: A autora (2020). 


\section{Capacitação em extensão promovida ou apoiada pela Pró-reitoria (ou equivalente) aberta à comunidade acadêmica}

Esse fato acaba reproduzindo a realidade encontrada pela própria Pró-reitoria no que tange à formação de seus servidores. No período analisado, a Proext não ofereceu nem apoiou nenhuma ação que visasse capacitar em extensão docentes, discentes ou técnicos administrativos, seja na promoção, gestão ou prática extensionista. É importante que em seu plano de ação, a Proext considere incluir tal ação em sua política de extensão, a fim de ampliar e qualificar a gestão e a realização das ações de extensionistas promovidas na Universidade.

\section{Garantia da qualidade na extensão}

A garantia da qualidade é compreendida pela existência de procedimentos formais e sistematizados para avaliação e aprovação de propostas, acompanhamento da execução e resultados de ações de extensão.

Nessa etapa do trabalho foram analisados os seguintes documentos: a) Deliberação no 125, de 6 de julho de 2006 - Aprovar a Proposta de Normatização das Atividades de Extensão da UFRRJ; b) Deliberação n. 18, de 26 de março de 2008 Aprovar a criação do Programa de Bolsas de Extensão no âmbito desta Universidade; c) Resolução $\mathrm{n}^{\circ}$ 1, de 12 de março de 2018 - estabelece normas e procedimentos para registro da ação de extensão "eventos" na Proext pelos coordenadores de cursos de graduação e pós-graduação da Universidade Federal Rural do Rio de Janeiro - UFRRJ; d) Resolução $n^{\circ}$ 4, de 7 de agosto de 2019 - Estabelece normas e procedimentos para Prestação de Serviço Voluntário em Ações de Extensão na Universidade Federal Rural do Rio de Janeiro - UFRRJ.

A análise documental permitiu constatar que a estrutura universitária conta com normas e procedimentos formais e sistematizados, no entanto, eles se encontram mais concentrados na fase de aprovação das propostas e dos resultados das ações de extensão (avaliação de resultado). Muito embora haja previsão normativa para o acompanhamento da execução das atividades de extensão, ainda não existe um procedimento formal que oriente e sistematize essa prática. 
É interessante observar que, em seu artigo 113, o Regimento Geral aponta para o regulamento da Extensão, um documento que normatizaria o funcionamento de programas e demais ações de extensão. A deliberação n ${ }^{\circ} 125$ de 6 de julho de 2006, que aprova as chamadas normas de atividades de extensão, atende, em parte, a essa notificação, entretanto, seria de grande importância a publicação de resoluções que regulamentassem as modalidades de ações que a atividade de extensão universitária supõe e que ainda não foram contempladas pelas resoluções ora em vigor (programas, projetos, cursos, prestações de serviço, etc.). Ou mesmo dar progresso ao manual da extensão com orientações sobre a elaboração de projetos e relatórios das ações de extensão, item também preconizado na deliberação CEPE nº 125, de julho de 2006.

Tema de grande relevância e que ainda carece de normatização, embora esteja em processo de construção na Universidade, é a creditação curricular das ações de extensão, que conta com a previsão legal de que seja destinado, no mínimo, $10 \%$ do total da carga horária curricular dos cursos de graduação para as atividades de extensão (MEC, 2018).

No que tange ao processo institucional de avaliação das ações extensionistas, recomenda-se retomar a iniciativa tomada em 2007 para constituição do Programa de Avaliação da Extensão (PAEX) (institucionalizada pelo processo $\mathrm{n}^{\circ}$ 23083.010892/2007-64). A retomada dessa ação, sob a forma de uma política de implantação do processo autoavaliativo da extensão, com detalhamento de estratégias e indicadores, é destacada pelo parecer emitido pela comissão do Conselho Nacional de Educação como uma das condições essenciais ao atendimento das diretrizes para as políticas de Extensão da Educação Superior brasileira (MEC, 2018).

Destaca-se que, desde 2017, a Proext tem investido na implementação de sistemas informatizados para registro das ações de extensão. Em 2018, houve a implementação do E-Cert - Sistema de Coordenação de Cursos, que é uma plataforma de certificação da Proext para simplificação do registro de eventos organizados pelos cursos de graduação e pós-graduação. De acordo com o Forproex (2007), o evento é caracterizado como "Ação que implica na apresentação e/ou exibição pública, livre ou com clientela específica, do conhecimento ou produto cultural, artístico, esportivo, científico e tecnológico desenvolvido, conservado ou reconhecido pela Universidade".

Em outubro do mesmo ano entrou em funcionamento o sistema SNCT, criado exclusivamente para gerenciar as atividades inscritas para o evento da Semana Nacional de Ciência e Tecnologia. No ano de 2019, a partir da implementação do módulo 
extensão do Sistema Integrado de Gestão de Atividades Acadêmicas (SIGAA) teve início um movimento de informatização dos processos de gestão da Proext. Tais iniciativas são capazes de impactar positivamente a habilidade da Proext em garantir melhores níveis de qualidade na extensão, bem como de ampliar a institucionalização das ações de extensão, tendo em vista seu potencial de tornar os procedimentos de registro, aprovação, acompanhamento e avaliação mais ágeis e atrativos.

\section{Taxa de aprovação de propostas de extensão em editais externos}

O período analisado evidencia tendência progressiva de queda na taxa de aprovação das propostas de extensão submetidas a editais externos, conforme o gráfico abaixo que representa o percentual da razão entre o número total de propostas de programas e projetos de extensão aprovados com financiamento, e o número total de propostas de programas e projetos de extensão submetidos.

Gráfico 4 - Taxa de aprovação de propostas em editais externos

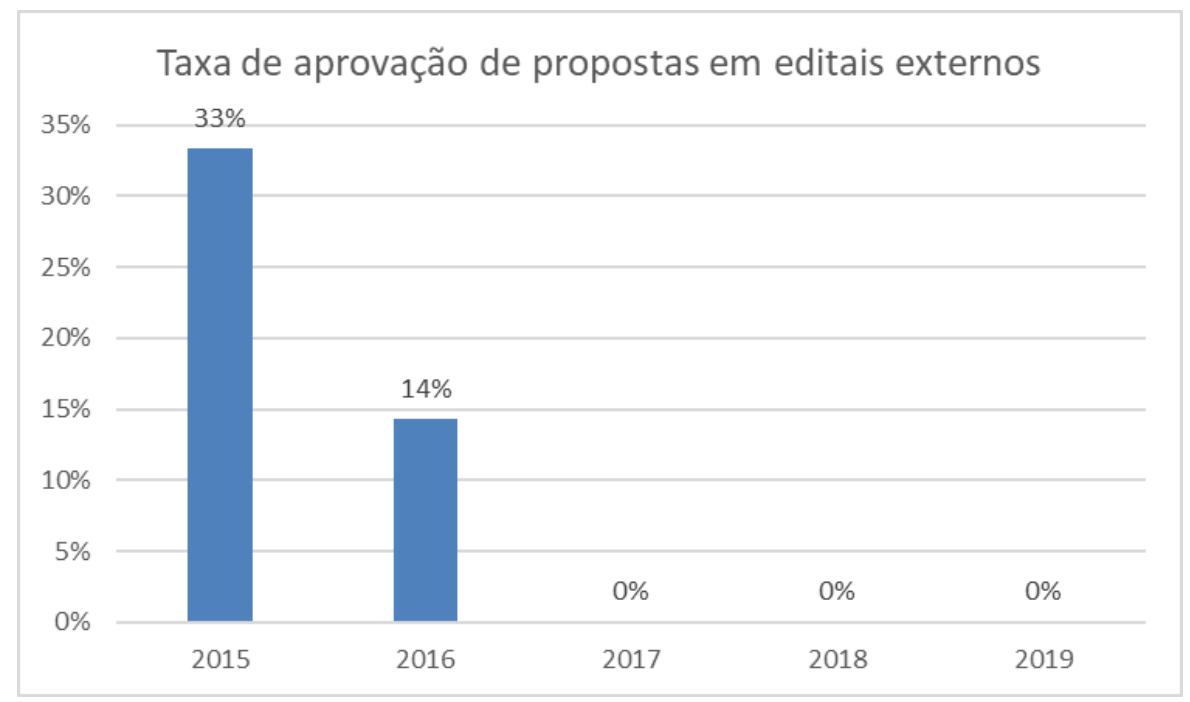

Fonte: A autora (2020)

Em 2015, a Proext participou de dois editais: PROEXT-MEC e Projeto Rondon, submetendo 12 propostas e aprovando 4. No ano de 2016, participou apenas do edital PROEXT-MEC, aprovando uma proposta dentre as 7 submetidas.

Esse comportamento de queda nas taxas observadas foi muito impactado pela suspensão do edital externo mais tradicional para o fomento da extensão universitária: o PROEXT-MEC. Criado em 2003, com o objetivo de apoiar as Instituições Públicas de 
Ensino Superior no desenvolvimento de programas ou projetos de extensão que contribuam para a implementação de políticas públicas, esse programa foi descontinuado em 2017. Ano em que a Proext da UFRRJ não teve nenhuma proposta encaminhada ou aprovada.

Entretanto, a partir de 2017 a Proext tem diversificado suas estratégias de atuação. Com isso, o financiamento de projetos internos tem ocorrido a partir da captação de recursos oriundos de emendas parlamentares e de parcerias externas, tais como a estabelecida recentemente com a Secretaria Municipal de Assuntos Estratégicos, Ciência, Tecnologia e Inovação (Semacti) da Prefeitura de Nova Iguaçu. Da parceria com a Prefeitura surgiu o Projeto (+ Casas da Inovação) que, com recursos do Ministério da Ciência, Tecnologia, Inovações e Comunicações, visa o fomento de ações para inclusão social e a inserção produtiva da população.

A captação de recursos parlamentares viabilizou o lançamento do programa de bolsas institucionais em Projetos de Extensão em Direitos Humanos (PDH) e a expansão do já consolidado Programa de Bolsas Institucionais de Extensão (BIEXT).

Por todo exposto, cabe destacar que a baixa performance nesse indicador tem sido contrabalanceada com iniciativas por ele não captadas, e que visam obter o mesmo resultado: garantir financiamento às ações de extensão.

\section{Taxa de conclusão de ações de extensão}

Não foi possível analisar com precisão esse indicador, já que os dados disponíveis junto aos atuais registros da Proext não permitem filtrar com precisão esse cruzamento de informações: previsão de conclusão e entrega do relatório final. Para concluir essa análise seria necessário consultar individualmente cada processo administrativo que formalizou a abertura das respectivas ações de extensão.

\section{Análise SWOT}

A fim de clarificar os aspectos analisados ao longo do trabalho e estruturar de forma concisa o diagnóstico aqui proposto, utilizou-se o esquema da matriz SWOT, cujo resultado é disponibilizado abaixo. 
Quadro 3 - Análise SWOT

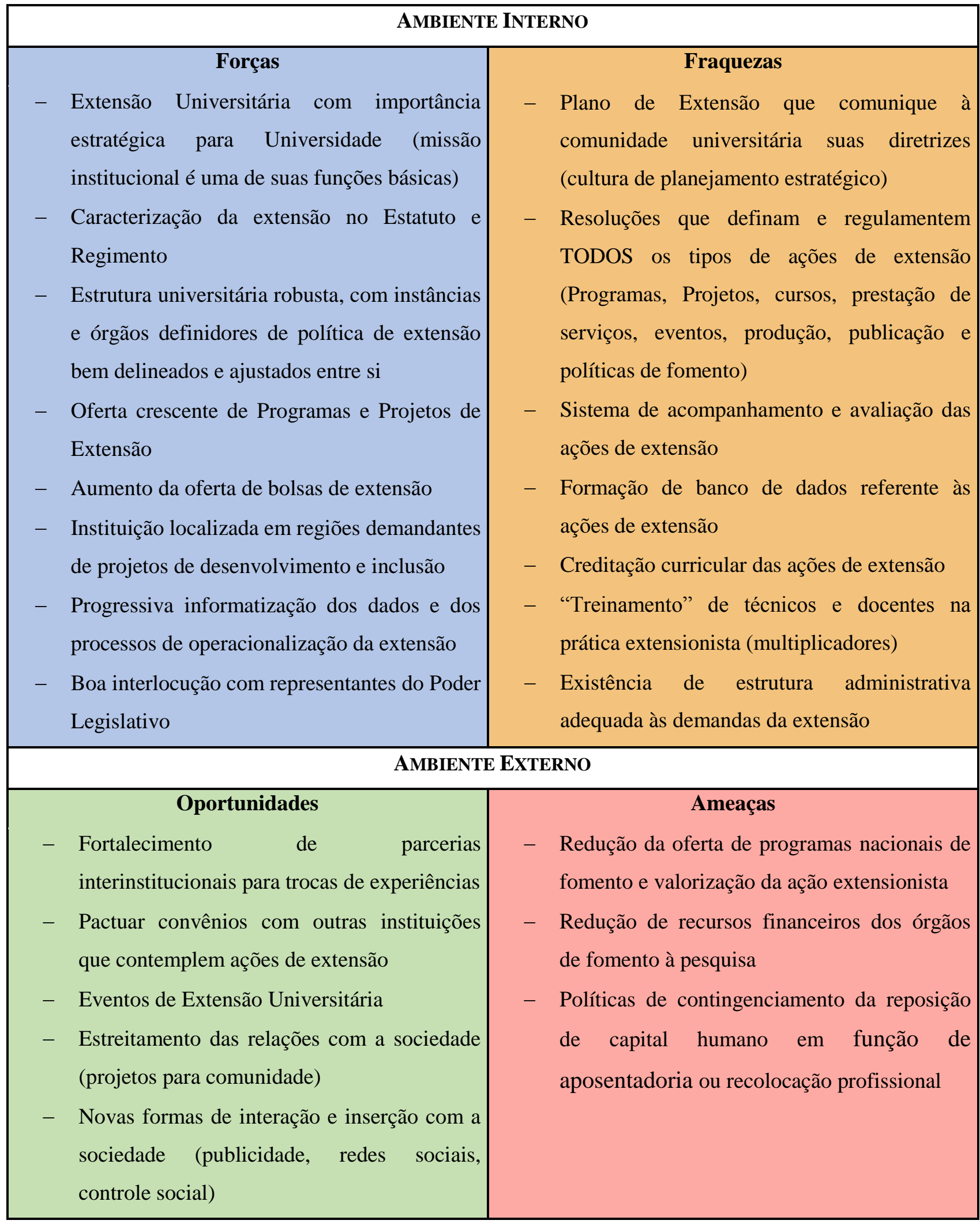

Fonte: A autora (2019). 


\section{CONSIDERAÇÕES FINAIS}

Finalizados os apontamentos a respeito dos indicadores e apresentada a análise SWOT, daremos prosseguimento a algumas reflexões que fazem parte do escopo deste trabalho. No que se refere à importância estratégica da extensão universitária para a instituição, verificou-se que a extensão universitária tem espaço dentro da estratégiamacro de ação da UFRRJ com foco em assumir o protagonismo de sua dimensão transformadora a partir do desenvolvimento de relações dialógicas entre universidade e sociedade. Relações essas que impactarão de forma decisiva a formação do estudante e a transformação social, indo além de uma política que apenas assume um viés assistencialista.

Em relação ao nível de sistematização da extensão, quando observamos as ações em nível estratégico, a UFRRJ apresenta uma estrutura universitária robusta, com instâncias e órgãos definidores de política de extensão bem delineados e ajustados entre si e capazes de dar suporte às demandas de institucionalização das ações extensionistas em suas diversas esferas.

Já no nível tático - estrutura de gestão -, a instituição possui um grau de sistematização elementar, que ainda carece preencher algumas lacunas importantes para o desdobramento dos ideais estratégicos (visão da instituição) em planos de ações menores que orientem a execução das tarefas em nível operacional. A ausência de um plano tático (plano de extensão) gera pouca clareza na comunicação dos objetivos a serem perseguidos institucionalmente.

O grau de informatização, ainda inicial e pulverizado (sem um sistema integrado), tem permitido agilizar os registros das ações extensionistas e certificar seus proponentes e participantes, entretanto, ainda é necessário caminhar no sentido de implementar em toda sua totalidade o módulo extensão do Sistema Integrado de Gestão de Atividades Acadêmicas (SIGAA) que a Universidade dispõe e, além disso, incorporar ao SIGAA o banco de dados existente nas plataformas temáticas que estão em funcionamento na Proext (E-Cert e Sistema SNCT). Também se põe como tarefa importante o aprimoramento do nível de publicidade (divulgação) das ações de extensão em andamento na Universidade.

No nível operacional seria importante investir na oferta de capacitação em extensão aos gestores e executores das ações de extensão, de modo a qualificar e despertar o interesse pelas práticas extensionistas. 
Por fim, apresentamos algumas sugestões para a elaboração de futuros trabalhos: avaliar os indicadores PG11, PG12 e PG13 da dimensão "Política de Extensão" da UFRRJ, que não foram abordados aqui; e analisar as demais dimensões, e seus respectivos indicadores, que integram o sistema avaliação nacional da extensão universitária (infraestrutura, relação universidade-sociedade, plano acadêmico e produção acadêmica), que no âmbito da UFRRJ ainda não foram investigados.

\section{REFERÊNCIAS}

ALENCAR, A. P. Tipos de estudo e introdução à análise estatística. 2012.

Disponível em:

https://www.ime.usp.br/ lane/home/MAE0317/AnaliseEstatisticaLane.pdf. Acessado em: 14 fev. 2020.

ASSOCIAÇÃO BRASILEIRA DE NORMAS TÉCNICAS. NBR 6023: informação e documentação: referências: elaboração. Rio de Janeiro: ABNT, 2002. 24 p.

ASSOCIAÇÃO BRASILEIRA DE NORMAS TÉCNICAS. NBR 10520: informação e documentação: citações em documentos: apresentação. Rio de Janeiro: ABNT, 2002. 7 p.

BIROCHI, R. Metodologia de estudo e de pesquisa em administração. Florianópolis: UFSC; Brasília: CAPES: UAB, 2015.

BRASIL. Conselho Nacional de Educação. Resolução CNE/CES n ${ }^{\circ}$, de 18 de dezembro de 2018. Estabelece as Diretrizes para a Extensão na Educação Superior Brasileira e regimenta o disposto na Meta 12.7 da Lei n. 13.005/2014, que aprova o Plano Nacional de Educação - PNE 2014 - 2024 e dá outras providências. Diário Oficial da União, Brasília, 19 de dezembro de 2018, Seção 1, p. 49 e 50. Retificação publicada no DOU de 18/2/2019, Seção 1, p. 28: Na Resolução CNE/CES n. 7, de 18 de dezembro de 2018, publicada no Diário Oficial da União de 19/12/2018, Seção 1, pp. 49 e 50, Seção 1. Disponível em:

http://portal.mec.gov.br/index.php?option=com_docman\&view=download\&alias $=1042$ 51-rces007-18\&category_slug=dezembro-2018-pdf\&Itemid=30192. Acesso em: 30 jan. 2019.

BRASIL. [Constituição (1988)]. Constituição da República Federativa do Brasil. Brasília, DF: Senado Federal, 1988. Disponível em:

http://www.planalto.gov.br/ccivil_03/constituicao/constituicao.htm. Acesso em: 4 out. 2017.

COSTA, F. L. D.; CASTANHAR, J. C. Avaliação de programas públicos: desafios conceituais e metodológicos. Revista da Administração Pública, Rio de Janeiro, v. 37, n. 5, p. 969-992, set./out. 2003. Disponível em:

https://bibliotecadigital.fgv.br/ojs/index.php/rap/article/view/6509. Acesso em: 14 fev. 2020. 
FORPROEX. Comissão Permanente de Avaliação da Extensão. Avaliação da Extensão Universitária: práticas e discussões da Comissão Permanente de Avaliação da Extensão. Belo Horizonte: FORPROEX/CPAE; PROEX/UFMG, 2013. Disponível em: https://www.ufmg.br/proex/renex/images/avalia\%C3\%A7\%C3\%A3o_da_extens\%C3\% A3o-_livro_8.pdf. Acesso em: 1 set. 2019.

FORPROEX. Conceito de extensão, institucionalização e financiamento. Rede Nacional de Extensão, 1987. Disponível em:

https://www.ufmg.br/proex/renex/images/documentos/1987-I-Encontro-Nacional-doFORPROEX.pdf. Acesso em: 16 jan. 2017.

FORPROEX. Avaliação Nacional da Extensão Universitária. Brasília: MEC/SESU; Curitiba: UFPR; Ilhéus: UESC, 2001. (Coleção Extensão Universitária; v. 3).

Disponível em: https://www.ufmg.br/proex/renex/images/documentos/AvaliacaoExtensao.pdf. Acesso em: 15 maio 2021.

FORPROEX. Extensão Universitária: organização e sistematização. Belo Horizonte: Coopmed, 2007. Disponível em:

https://www.ufmg.br/proex/renex/images/documentos/Organizacao-e-

Sistematizacao.pdf. Acesso em: 16 maio 2021.

FORPROEX. Plano Nacional de Extensão Universitária. Belo Horizonte: PROEX, 1999. (Coleção Extensão Universitária; v. 1). Disponível em:

https://www.ufmg.br/proex/renex/. Acesso em: 4 out. 2017.

FORPROEX. Indicadores Brasileiros de Extensão Universitária. Campina Grande: EdUFCG, 2017.

FREY, K. Políticas públicas: um debate conceitual e reflexões referentes à prática da análise de políticas públicas no Brasil. Planejamento e Políticas Públicas, Rio de Janeiro, n. 21, p. 211-259, 2000. Disponível em:

https://www.ipea.gov.br/ppp/index.php/PPP/about/contact. Acesso em: 14 fev. 2020.

GIL, A. C. Como elaborar projetos de pesquisa. 4. ed. São Paulo: Atlas, 2008.

GATTI, B. A. Avaliação da extensão universitária: da institucionalização às suas práticas. Revista Brasileira de Extensão Universitária, Santa Catarina, v. 2, n. 2, p. 22-27, jul./dez. 2004. Doi: 10.36661/2358-0399.2004v2i2.894. Disponível em: https://periodicos.uffs.edu.br/index.php/RBEU/article/view/894. Acesso em: 20 jan 2019.

JANNUZZI, P. D. M. Indicadores para diagnóstico, monitoramento e avaliação de programas sociais no Brasil. Revista do Serviço Público, Brasília, v. 56, n. 2, p. 137160, abr./jun. 2005. Doi: 10.21874/rsp.v56i2.222. Disponível em: https://revista.enap.gov.br/index.php/RSP/article/view/222. Acesso em: 14 jan. 2019.

CAUCHICK-MIGUEL, P. A. et al. Metodologia de pesquisa em engenharia de produção e gestão de operações. Rio de Janeiro: Elsevier, 2012. 
MINAYO, M. C. de S. (org.). Pesquisa social: teoria, método e criatividade. 18. ed. Petrópolis: Vozes, 1994.

SANTOS, R. de C. L. F. dos. Orçamento público. Florianópolis: UFSC; Brasília: CAPES: UAB, 2011.

SECCHI, L. Políticas públicas: conceitos, esquemas de análise, casos práticos. São Paulo: Cengage Learning, 2010.

SOUZA, C. Políticas públicas: uma revisão de literatura. Sociologias, Porto Alegre, $\mathrm{n}$. 16, p. 20-45, jul./dez. 2006. Doi: 10.1590/S1517-45222006000200003. Disponível em: https://www.scielo.br/j/soc/a/6YsWyBWZSdFgfSqDVQhc4jm/abstract/?lang=pt.

Acesso em: 13 maio 2020.

TREVISAN, A. P.; VAN BELLEN, H. M. Avaliação de políticas públicas: uma revisão teórica de um campo em construção. Revista da Administração Pública, Rio de Janeiro, v. 42, n. 3, p. 529-550, maio/jun. 2008. Doi: 10.1590/S003476122008000300005. Disponível em: https://bibliotecadigital.fgv.br/ojs/index.php/rap/article/view/6644. Acesso em: 10 jan. 2020.

UNIVERSIDADE FEDERAL RURAL DO RIO DE JANEIRO. Conselho

Universitário. Deliberação $n^{\circ} 15$, de 23 de março de 2012. Disponível em: http://institucional.ufrrj.br/soc/files/2018/10/Delib015CONSU2012Regimento.pdf. Acesso em: 15 set. 2019.

UNIVERSIDADE FEDERAL RURAL DO RIO DE JANEIRO. Conselho de Ensino, Pesquisa e Extensão. Deliberação $n^{\circ}$ 125, de 6 de julho de 2006. Aprovar a Proposta de Normatização das Atividades de Extensão da UFRRJ. Disponível em: http://www.ufrrj.br/portal/modulo/dext/formularios/normas_de_extensao.pdf. Acesso em: 17 set. 2019.

UNIVERSIDADE FEDERAL RURAL DO RIO DE JANEIRO. Coordenadoria de Comunicação Social. História da UFRRJ. Rio de Janeiro, 2019. Disponível em: http://institucional.ufrrj.br/ccs/historia-da-ufrrj/. Acesso em: 25 ago. 2019.

UNIVERSIDADE FEDERAL RURAL DO RIO DE JANEIRO. Pró-Reitoria de Extensão. Resolução ${ }^{\circ} 1$, de 12 de março de 2018. Estabelece normas e procedimentos para registro da ação de extensão "eventos", na Proext pelos Coordenadores de cursos de graduação e pós-graduação da Universidade Federal Rural do Rio de Janeiro UFRRJ, 2018.

UNIVERSIDADE FEDERAL RURAL DO RIO DE JANEIRO. Pró-Reitoria de Extensão. Resolução n ${ }^{\circ}$ 3, de 16 de maio de 2019. Estabelece normas e procedimentos que constituem o Regimento Interno da Câmara de Extensão da Universidade Federal Rural do Rio de Janeiro - UFRRJ, 2013.

UNIVERSIDADE FEDERAL RURAL DO RIO DE JANEIRO. Pró-Reitoria de Extensão. Resolução ${ }^{\circ}{ }^{1}$, de 17 de abril de 2019. Estabelece normas e procedimentos 
que constituem o Regulamento da Escola de Extensão (Ext-Escola) da Pró-Reitoria de Extensão da Universidade Federal Rural do Rio de Janeiro - UFRRJ, 2019.

VIANA, A. L. Abordagens metodológicas em políticas públicas. Revista de Administração Pública, Rio de Janeiro, v. 30, n. 2, p. 5-43, mar./abr. 1996. Disponível em: https://bibliotecadigital.fgv.br/ojs/index.php/rap/article/view/8095. Acesso em 3 mar. 2019.

Submetido em 29 de agosto de 2021.

Aprovado em 7 de novembro de 2021. 


\section{ANEXO A - Quadro Analítico dos Indicadores}

Indicador: PG1 Importância estratégica da Extensão Universitária

Objetivo: Avaliar a presença da extensão na definição da missão institucional da IES.

Unidade de medida: qualitativa binária - sim ou não

Resultado da análise: Sim

Indicador: PG2: Estrutura organizacional de suporte a extensão universitária

Objetivo: Identificar na IES a existência de órgãos definidores de políticas de extensão, responsáveis pela implementação de normas e regulamentações.

Unidade de medida: Qualitativa binária - sim ou não

Resultado da Análise: Sim

Indicador: PG3 - Institucionalização de programas e projetos de extensão

Objetivo: Avaliar o nível de oferta aos alunos matriculados na instituição, em regime presencial, de programas e projetos institucionalizados.

Unidade de medida: Quantitativa, proporção - alunos/programas e projetos

Resultado da Análise: $\mathrm{N}^{\circ}$ de alunos de graduação presencial matriculados no ano / $\mathrm{N}^{\circ} \mathrm{de}$ programas e projetos institucionalizados

Vide gráfico 1

Indicador: PG4 - Valorização da prática extensionista como critério de promoção na carreira

Objetivo: Avaliar a incorporação de critérios de promoção funcional associados ao envolvimento em ações de extensão no Plano de Carreira dos Servidores.

Unidade de medida: Qualitativa binária - sim ou não

Resultado da Análise: sim

Indicador: PG5 - Formação em gestão da extensão para servidores dos órgãos/setores responsáveis pela extensão

Objetivo: Avaliar a proporcionalidade do número de horas de treinamento em Gestão da Extensão Universitária disponibilizada anualmente aos servidores (incluindo gestores).

Unidade de medida: Quantitativa, proporção: horas de treinamento/servidor

Resultado da Análise: $\mathrm{N}^{\circ}$ de servidores da extensão capacitados no ano/ $\mathrm{n}^{\circ}$ total de servidores da extensão 
Indicador: PG6 - Participação dos servidores da extensão em eventos da área Objetivo: Avaliar a proporcionalidade do número de eventos e congressos de extensão universitária com a participação de servidores da extensão (incluindo gestores).

Unidade de medida: Quantitativa, proporção: eventos/servidor

Resultado da Análise: $N^{o}$ de participações ativas em eventos/ número total de servidores da extensão

\section{Vide gráfico 3}

Indicador: PG7 - Capacitação em extensão promovida ou apoiada pela Pró-Reitoria (ou equivalente) aberta à comunidade acadêmica

Objetivo: Avaliar a participação em treinamentos em extensão de docentes, técnicos e alunos de modo a despertar o interesse pela prática extensionista.

Unidade de medida: Proporção: participantes/eventos

Resultado da Análise: = $\mathrm{N}^{\mathrm{o}}$ de participantes capacitados no ano $/ \mathrm{N}^{\circ}$ total de eventos promovidos por ano

No período considerado não foram encontrados registros de ações desta natureza.

Indicador: PG8 - Garantia da qualidade na extensão

Objetivo: Identificar a existência de procedimentos formais e sistematizados para avaliação e aprovação de propostas, acompanhamento da execução e resultados de ações de extensão.

Unidade de medida: Qualitativa, binária - sim ou não

Resultado da Análise: sim

Indicador: PG9 - Taxa de aprovação de propostas de extensão em editais externos

Objetivo: Avaliar o percentual de projetos e programas submetidos e aprovados em editais externos

Unidade de medida: Quantitativa, percentual (\%)

Resultado da Análise: ( $\mathrm{N}^{\circ}$ total de propostas de programas e projetos de extensão aprovados com financiamento/ $\mathrm{N}^{\mathrm{o}}$ total de propostas de programas e projetos de extensão submetidos) $\mathrm{x}$ 100

\section{Vide gráfico 4}


Indicador: PG10 - Taxa de conclusão de ações de extensão

Objetivo: Identificar o quantitativo de ações de extensão concluídos no tempo pré-definido (com apresentação de relatório final).

Unidade de medida: Quantitativa, percentual (\%)

Resultado da Análise:

$\left(\mathrm{N}^{o}\right.$ anual de ações de extensão finalizadas no prazo $/ \mathrm{N}^{o}$ total de ações com prazo para acabar no ano) $\mathrm{x} 100$

Não foi possível efetuar a análise por falta de dados.

Fonte: A autora (2020) adaptado de Forproex (2017). 